\title{
Arqueologia em Movimento: uma análise dos métodos para a investigação de movimentos de pessoas, objetos e ideias no passado
}

Cláudia Regina Plens*

Universidade Federal de São Paulo, São Paulo-SP

Beaudry, Mary C.; Parno, Travis G. (Eds.). Archaeologies of Mobility and Movement. Nova Iorque: Springer, 2013.

Mobilidade e movimento são conceitos há muito utilizados na Arqueologia, desde quando difusão e migração foram utilizados, por Gordon Childe, para explicar as mudanças culturais. Tratar das relações entre pessoas passa, impreterivelmente, por esses temas. Contudo, os autores desse livro se propõem a analisar a questão de mobilidade e movimentação a partir de enfoques diversos e mais abrangentes, como nostalgia, perda, saudade e rupturas.

$\mathrm{Na}$ Arqueologia Histórica essa temática foi abordada no encontro intitulado Contemporary and Historical Archaeological Theory, em 2011, na Universidade de Boston (EUA), sob o tema "People and things in motion", de onde se desdobrou a confecção desse livro.

Assim como os artefatos, as paisagens e os lugares também têm seu ciclo de vida, eles são utilizados, marcados, modificados, reutilizados e, por fim, abandonados. Con- tudo, como vemos nesse compêndio, nem sempre com o mesmo significado.

Da mesma forma, a existência do lugar depende das inúmeras interações entre pessoas e determinado espaço, resultando em diferentes histórias de vida que modificam os espaços constantemente, conferindo diferentes ressignificados na atualidade, na memória social.

O capítulo 1, uma introdução escrita pelos editores, traz uma importante síntese da história da Arqueologia no que se refere aos temas de movimentação e mobilidade. Além disso, faz um resumo dos artigos apresentados no livro ressaltando onde localizar a questão de movimentação e mobilidade nos temas abordados. O livro traz os artigos organizados em três partes distintas: "Objects in Motion", "People in Motion" e "Movement Through Spaces". Essas partes, no entanto, parecem estruturadas mais segundo uma razão de escolha particular dos organizadores do que propriamente por algum significado que os interligue.

O capítulo 2, escrito por Visa Immonen, discorre sobre o sistema do colonialismo ologia Forense (CAAF/Unifesp). Coordenadora do Laboratório de Estudos Arqueológicos (LEA/Unifesp). E-mail: clauplens@gmail.com. 
entre grupos indígenas de duas diferentes regióes, Lapônia e uma colônia sueca na América do Norte, e examina como a cultura material é transmitida e apropriada por diferentes grupos culturais. Da perspectiva da movimentação, o artigo aborda diferentes escalas regionais, micro e macro, para apontar que os grupos culturais conferem, aos objetos de origem exógena, uma ressignificação dentro de seus próprios conceitos culturais.

O capítulo 3, escrito por Scott Joseph Allen, trata de uma questão da Arqueologia Histórica brasileira. Mais uma vez, as questôes de mobilidade e movimentação são relacionadas com encontros culturais coloniais. A partir da análise de cachimbos de argila vermelha, $o$ autor aponta que, diferentemente do que havia sido sugerido anteriormente pela literatura, esses cachimbos não são relacionados com um grupo cultural particular, mas a vários grupos de diferentes áreas geográficas. Para tanto, o autor se baseia na premissa da importância de se conhecer o ciclo de vida do objeto, desde sua manufatura até seu descarte final, para a compreensão das relaçôes dos grupos envolvidos, pois a articulação dos grupos culturais na cadeia operatória pode elucidar a fusão, a relação e a movimentação entre os agentes produtores e usuários dos objetos. Nesse sentido, o autor aponta a necessidade de se estudar os grupos coloniais de forma integrada em um sistema social e não mais isoladamente.

O capítulo 4, escrito por Oscar Aldred, traz um tema mais recente, uma fazenda de ovelhas da Islândia de meados do século XIX e início do século XX, para explicar como ob- jetos e espaços estáticos podem explicar relações de movimentos entre pessoas e animais. A partir da conceitualização de mobilidade e movimento, sendo o ponto-chave a questão de poder, ele aponta que quem controla os animais e é responsável pela movimentação de pessoas detém o poder.

No capítulo 5, Ronald Salzer trata de um tema frequente na Arqueologia: como objetos singulares podem sugerir mobilidade e movimentação entre distâncias geográficas. Para tanto, o objeto analisado é o relógio do sol. A partir de um achado nas proximidades de Viena, no Castelo de Grafendorf, o autor trata da noçáo de cálculo do tempo para percorrer distâncias e para a interação entre grupos de distintas localidades geográficas.

O capítulo 6, escrito por Chieh-fu Jeff Cheng e Ellen Hsieh, trata de questóes relacionadas com a colonizaçáo chinesa em Taiwan, especialmente acerca da perda de identidade atrelada à questão de memória.

Mats Burström, no capítulo 7, traz um surpreendente trabalho acerca de objetos, sem, contudo, os localizar. Referindo-se aos objetos enterrados pelos refugiados da Segunda Guerra da Estônia, o autor analisa como esses objetos simbolizaram o elo invisível de esperança de retorno a suas terras, que se perpetuou na memória das famílias por geraçóes.

No capítulo 8, Craig N. Cippola examina uma questão referente à movimentação populacional de larga escala entre grupos indígenas norte-americanos. Por meio da organização espacial de residências, cemitério, cestarias, bem como suas comemoraçóes 
e linguagem, o autor aponta que, ao longo do tempo, houve reconfiguração das relaçôes sociais entre indivíduos de diferentes ancestralidades na formação do que passou a ser chamado Brothertown Indians, em Wisconsin.

O capítulo 9, escrito por Sean Winter, analisa o sistema britânico de transporte de condenados a partir de 1600 . Nessa pesquisa náo são estudados sítios arqueológicos, mas trajetos de transporte de pessoas, de bens materiais que mantinham o sistema de condenação, assim como as ideias e políticas por trás desse sistema. $\mathrm{O}$ autor aponta que a condenação em outros territórios teve diferentes motivaçóes, muitas vezes o uso intensivo do trabalho, mais do que uma reforma do condenado.

Karen A. Hutchins, no capítulo 10, trata do movimento não apenas no seu aspecto físico, mas em termos de rupturas, mudanças e progresso, trazendo a movimentação social e política como influência no modo de vida de pessoas e famílias, podendo ser notado pelas mudanças de posiçóes, valores e status. Para tanto, o artigo desenvolve um importante aspecto da história das cidades, a marginalização - e exclusão -, dos indivíduos menos abastados, assim como seus modos de resistências, em Massachusetts (EUA).

No capítulo 11, Magdalena Naum aborda um fator importante no estudo da movimentação de pessoas, a nostalgia. Assim como toda a imaterialidade, esse sentimento se concretiza materialmente no ambiente construído pelo indivíduo. Dessa forma, a autora aborda como espaços e objetos na Nova Suécia, nos Estados Unidos, simbo- lizavam o que foi perdido pelos indivíduos com a imigração.

No capítulo 12, os autores John $\mathrm{H}$. Cherry, Krysta Ryzewsku e Luke J. Percoraro, inspirados pelo estudo clássico de Pompeia, se propóem a analisar um remanescente de uma catástrofe da atualidade, o furacáo Hugo, que pôs fim no estúdio de música AIR Studios, em Monserrat, Caribe. Preocupados em causar impacto no leitor a partir da comoçáo pelo evento dramático da destruição e pela história do local (e, consequentemente, menos embasados em métodos e interpretaçôes arqueológicos), os autores fazem uma descrição de seus trabalhos de campo e mostram como espaços da cultura moderna têm potencial para se tornar patrimônio. Os autores propóem uma leitura diferente dos espaços de movimentaçáo, nesse caso, AIR Studios é visto como espaço que congrega e converge a movimentação entre pessoas (estrelas do rock e público) e objetos, de CDs e ideias, à música.

No capítulo 13, Travis G. Parno faz uma leitura do papel de pequenos museus e seus conceitos expositivos. Para tanto, o autor analisa como que as informaçóes chegam e são interpretadas pelos visitantes. Trata-se de um estudo das narrativas museológicas e das diferentes percepçôes sobre o passado.

No capítulo 14, Christina J. Hodge traz uma importante contribuição, a análise das primeiras estruturas que deram origem a Universidade de Harvard. A principal estrutura a ser analisada é a "Harvard Indian College" que, em 1655, era destinada ao ensino de alunos indígenas. $\mathrm{O}$ artigo, com maior emprego de pesquisa de campo e análise ar- 
tefatual desta coletânea, traz interessantes informaçóes sobre os aspectos conceptivos do que se tornou a primeira universidade da América do Norte, e o papel dos grupos indígenas na sua origem, possibilitando interpretaçóes importantes a partir do confronto entre o documento escrito e a cultura material. Contudo, o artigo soa como uma análise inacabada, onde as interpretaçóes dos dados arqueológicos estâo ainda por acontecer, sendo a conclusão bastante inocente e pouco embasada.

No capítulo 15, Alexander Keim, mais baseado em uma arqueologia da paisagem urbana, faz uso de uma metodologia comum, mas que funciona adequadamente para o ambiente urbano, análise de mapas, fotografias, e dados históricos e arqueológicos. Com essa metodologia o autor consegue avançar na compreensão das práticas e significados da vida urbana da cidade de Boston do século XIX.

De modo geral, os temas de pesquisa são interessantes e faz arqueólogos e historiadores repensarem em possibilidades de projetos para a compreensão do passado recente. No entanto, os autores, que se propóem a fazer uma Arqueologia da Mobilidade e do Movimento, chegam aos temas de mobilidade e movimento como resultado, mais do que como foco central das pesquisas.

Se, por um lado, são poucos os capítulos que tratam da questáo espacial propriamente dita (com exceção dos capítulos 4 e 8), tal como pode ser cogitado pelo título do livro, por outro, a publicaçáo prima por trazer à tona questóes como memória, identidade, rupturas culturais que se desenvolveram a partir das relaçóes de movimentação e mobilidade entre pessoas e objetos.

Os autores também fazem muito mais uso da documentação histórica do que arqueológica, deixando um vazio metodológico para a arqueologia da Mobilidade e do Movimento. Na perspectiva metodológica, o livro Landscapes of Movement: Trails, Paths and Roads in Anthropological Perspective, organizado por James E. Snead e Clark E. Erikson, aponta propostas metodológicas mais consolidadas.

Para compreensão do que é a Arqueologia da Mobilidade e do Movimento, se faz necessária a leitura do capítulo introdutório e do posfácio, o primeiro escrito por Mary C. Beaudry e Travis G. Parno e o segundo por Shannon Lee Dawdy, onde, em poucos parágrafos, as autoras conseguem sintetizar um histórico das pesquisas nesses campos e relacionar o que de mobilidade e movimentaçáo pode se encontrar nos artigos.

Diferentemente da Arqueologia tradicional, que foca na análise de um único sítio por vez (como é ressaltado no capítulo 8), o livro se destaca por pesquisas que fazem um percurso distinto, sendo que grande parte dos capítulos se dispóe a interpretar a relação dos múltiplos espaços. Por essa razão, os artigos disparam um gatilho interessante, o de repensar na Arqueologia Histórica a partir de outros enfoques para se compreender ainda mais profundamente aspectos do comportamento humano do passado, que geralmente os arqueólogos não se permitem perguntar, sobretudo quanto ao impacto da mobilidade e movimento náo somente no âmbito social, mas sobre os indivíduos. 